\title{
Cambios Culturales en los AsháninKa Desplazados
}

\author{
Beatriz Fabián
}

"A las mujeres asháninkas

por su valor y sabiduría, compositoras e intérpretes

de su arte..."

En esteestudio, la autora, a partir dela recopilación y transcripción meticulosa de las canciones asháninka entonadas por los nativos que en un momento estuvieron sometidos involuntariamente a la dinámica del grupo terrorista Sendero Luminoso, hace una reflexión acerca de los cambios de identidad del grupo étnico Asháninka, a partir de su contacto con los integrantes de S.L., provenientes generalmente de la sierra peruana, asícomo de la penetración de ritmos de diversa procedencia que ha llevado al sincretismo musical con su correlativo influjo en la identidad grupal Asháninka.

In this study the author, using a recording and meticulous transcription of Ashaninka songs intoned by the natives, who at one time were involuntarily subdued to the dynamics of theShining Path terrorist group, reflects on the changes in identity of the Ashaninka after their contact with members of the Shining Path group. The latter are from highland Peru, and the penetration of rythms from that area has resulted in musical syncretism with its corresponding influence on Ashaninka group identity. 


\section{INTRODUCCION}

La selva central ${ }^{(1)}$ es una de las regiones más convulsionadas por la violencia política. Durante mucho tiempo ésta fue una zona de tránsito, de aprovisionamiento y de refugio para los grupos alzados en armas, pero en los últimos 7 años la situación se ha agravado por el frecuente accionar de estos grupos y su lucha por el control de la zona (Espinosa 1994: 1).

La zona de selva central por su ubicación geopolítica, constituye puerta de entrada y de salida hacia las diversas ciudades de sierra,centro y sur del país.

A inicios del noventa S.L. controlaba casi la totalidad del ámbito provincial de Satipo incluyendo zonas campesinas y nativas,manteniéndose en estado de emergencia desde 1988 hasta la actualidad;esto dio origen a la organización de los comités de autodefensa (rondas nativas,rondas campesinas y rondas urbanas) que sobrepasan los 200 comités.

El accionar de S.L. se caracterizó inicialmente por ataques a las comunidades nativas, misiones religiosas, y proyectos de desarrollo, invitando a "integrarse a la lucha armada" luego de arengas y discursos proselitistas.

En un segundo momento se llevan a jóvenes,unos voluntariamente y otros a la fuerza, para formar las "escuelas populares",incluso llegaron a capturar a comunidades nativas íntegras dentro del período del "arrasamiento".

En un tercer momento se constituyen las "bases de apoyo" donde habían organizado a la población en diversos contingentes: "frente mayor", "bloques de contención","socorro popular", entre otros.

Los mandos ("cuadros políticos y militares"), generalmente eran jóvenes provenientes de la sierra e incluso ahí habían mujeres bilingües y varones en general. Nuestras entrevistadas señalan: "nos daban tareas para sacar letras de canciones revolucionarias en asháninka". Además, puestos bajo vigilancia a fin de que no fugaran, si eran descubiertos o alcanzados en el trayecto por las trochas ${ }^{(2)}$ eran sometidos a muerteen reuniones públicas, como amedrentamiento al que se proponia huir.

A principios de 1991, se calculaba que unos 10,000 asháninka estaban en manos de S.L.,ese mismo año en el río Ene el comité de autodefensa rescataba 2,800 asháninkas y en 1993 en el río Tambo y Bajo Perené los recuperados eran 
más de mil. En la actualidad se calcula que quedan unos 4,000 nativos prisioneros de S.L.(Espinosa 1994: 4).

Sendero, había perdido importantes "bases de apoyo" ante la fuga masiva y el arrepentimiento de sus principales "mandos asháninka",por esta situación estaría en una retirada estratégica de los ríos Tambo y Ene hacia el territorio poblado por piros y nomatsiguengas, miembros de la autodefensa señalan que las huellas por el monte se dirigen hacia el río Urubamba.Corre el rumor de que varias columnas armadas habrían cruzado la frontera del Perú hacia el Brasil.Antes de esto, S.L. liberó a numerosos asháninkas que se encontraban como prisioneros en las "bases de apoyo".

La pacificación en Selva Central es aún incierta por ahora, ya que la zona es de alta convulsión política. S.L., recompone sus fuerzas, para continuar la "lucha armada", con la fuerza más cruenta, con todo los medios a su alcance. Así, en varias ocasiones los pobladores detectaron huellas y espías, durante las noches de luna y en días de lluvia que son los momentos propicios para sus operaciones; también dejaron papeles manuscritos que decían "barreremos y dejaremos en cenizas a las cabezas negras de Poyeni y Betania". En noviembre de 1994,cerca de 40 senderistas armados intentaron atacar Betania lanzando también vivas al "Presidente Gonzalo". A todo esto, la población queda presa de una paranoia colectiva.

De otro lado, la Ley de Arrepentimiento promulgada por la Nueva Constitución Política del Estado (Oct. 93) no tiene clara la distinción para los desplazados asháninkas. La característica central, radica en que estuvieron con SL nopor decisión propia, sino quefueronobligados a participar, diferenciándose de aquellos que tomaron parte activa en las acciones bélicas y asesinatos.

La problemática de las familias desplazadas al estar concentradas en el núcleo poblacional, se agudiza por el hostigamiento de los ronderos, escasez de alimentos, chacras restringidas, enfermedades, carencia de materiales educativos, viviendas, entre otros. $Y$ por el espacio limitado, las tensiones sociales existentes en cualquier momento pueden estallar en acciones de violencia, que podrían llegar hasta la muerte. 


\section{INSPIRACION MUSICAL Y ACONTECER HISTORICO}

Las canciones que se presentan en forma testimonial, recogen gran parte de la expresión de las familias desplazadas en los núcleos poblacionales ${ }^{(3)}$, que se remonta al período cuando estaban en calidad de prisioneros en las filas de S.L. en las llamadas "zonas liberadas", donde muchos jóvenes formaban parte del denominado "Ejército Guerrillero" en calidad de "Combatientes" tanto en el "frente principal" y en "los bloques de contensión". Formaron las delegaturas de los "Comités Populares abiertos" y la mayor parte de la población, ya sea ancianos, adultos y niños integraron las "masas" en los múltiples "comités de apoyo".

También, rememoran a través de las canciones al período de la vivencia en sus comunidades antes de la violencia política. Incorporan asímismo a la vivencia actual en calidad de refugiados y a la secuela de la desestructuración de la familia, ausencia de los hijos jóvenes, presencia de niños huérfanos y viudas.

Las canciones las interpretan en círculos familiares o a nivel individual, generalmente en un ambiente de confianza, más no así ante personas extrañas. Las reuniones pueden ser de celebración de cumpleaños, bautizos, preparación de la adolescente ${ }^{(4)}$ donde beben abundante masato ${ }^{(5)}$.

Las canciones son interpretadas por los adolescentes, varones y principalmente por las mujeres.Los contenidos expresan estados anímicos de alegría, dolor, tristeza, decepción y desarraigo. Las canciones relatan la desilusión de los nativos desplazados por la presión y el engaño en las "bases de apoyo" o centros de retención político y militar donde participaban los nativos, obligados o por determinación voluntaria, bajo las consignas de "una vida mejor y un nuevo Estado".

El rol de "combatientes" que les tocó desempeñar a los asháninka los sometía a constantes peligros, desde la caída en las trampas artesanales ${ }^{(6)}$, morir destrozados por las bombas caseras o abaleados por las tropas antisubversivas, todo esto en un marco de rígida disciplina de la militancia senderista.

Esta situación los obligó a escapar de las filas de S.L. para entregarse a las FF.AA. acantonadas en los núcleos poblacionales apoyados por los Comités de Autodefensa. La modalidad de fuga o huida la hacían en forma colectiva o individual. Así muchos familiares de los desplazados permanecen detenidos aún en el contingente senderista,como testimonia la siguiente canción: 


\section{Novashiretaka Narori}

YUVASHIRETANAJEA IRINIRO TE

INIAJERI ITOMI PIANAKA JAUKARINKA

IKENANAQUERI YOJOKANAQUERI APANIAJI

YASHINONKANAYAJIA KUAJIKA ANTA NOMANPIKI

TERINKA JAUKARINKA IKENAYETA

ANTATOJASHIQUEPI YUVASHIRETANAJEA IRIYORI

IQUINKISHIATANAJERI IRINIRO IRIRI

NOVESHIRIACA NARORI NONIAVAJIRI NOTOMI

INOKAII IRIORI AKA POYENIKI

MEKA TIKATSI NOQUIRIQUISHIRIANEJ

YOCA YOVASHINONCAJAITIQUERIRI YORA

AMATABITANTATSIRI PAMAJENA COLLANA

Nosotros ahora vamos a cantar,

por la llegada de mi hijo,

que ha venido aqui.

Ha llegado a Poyeni,

estoy contenta,

nuestro hijo está

y nos ha encontrado

a toda la familia.

Nosotros en armonía

le hemos recibido

y le damos de comer de todo.

Vamos a tomar masato, para que se alegre, con la suegra, los hijos y familiares.

La madre relata la alegría, la comida y canta a la unidad familiar, que estaba resquebrajada por la ausencia del hijo mayor. Los asháninka desplazados al huir de las filas deSL., consideraban que en el núcleo poblacional iban a vivir en una situación mejor.

Sin embargo, aquí y en muchos casos, eran vistos con sospecha, pues podían ser posibles espías o infiltrados; eran considerados por tanto, casi como enemigos, tal vez aliados de S.L. 
El comité de au todefensa, los sometía a hostigamientos, castigos corporales, trabajos forzados y torturas, incluyendo a niños, mujeres y varones, respecto a esta actitud expresan que la población asháninka desplazada, anhela retornar a sus comunidades de origen, desean un mundo mejor de paz y tranquilidad, ellos dicen "... hemos salido aquí para vivir mejor con nuestros hijos y no para seguir viviendo oprimidos", y como no los dejan salir se sienten una especie de "prisioneros", así cantan:

Novashirireta

NOVASHIRIRETA NOMANPIKI NARORI

NOKENKE SHIRETIRO NOIRIN KAYATEKI

NOSHIYA KANTA PAIRO NONAMPIKI NARORI

NOKE NAKENATAKE NOIRINKAYATEKI

\section{Estoy Triste}

Yo estoy triste

en esta comunidad

estoy pensando en mi sitio

yo no estoy alegre como allá

yo quiero ir en mi sitio.

Los asháninka que formaron parte del "Frente Principal" y de la "masa" en las "bases de apoyo", cantaban canciones denominadas "revolucionarias", que les enseñaban los mandos senderistas, así narran:

\section{Noijoteri Narori Yora Akenari}

\section{Anta Umanaromuteki}

Con los que me han agarrado, voy a luchar con ellos,

a donde van, voy a ir a la guerra.

Describe la disposición para ir a la guerra, aunque existe previa resignación cuando se enuncia "con los que me han agarrado", sintiéndose víctimas de haber sido prisioneros de S.L., la correlación de fuerzas y su estado de cautiverio los lleva a proclamar consignas como "que su vida pertenece al partido". 
En las "Escuelas Populares", las niñas estaban sometidas a la enseñanza del Nuevo Estado, a cantar y a hacer palmadas.

Asimismo, cuentan que los niños en las "bases de apoyo" eran considerados como la "legión del futuro", cantaban canciones y diseñaban emblemas senderistas. Muchos nacieron y crecieron ahí, pues sus padres llevaban de 6 a 7 años en dichas "bases". Cierto día, un grupo de niños de padres arrepentidos que jugaban en la plaza de un núcleo poblacional, de pronto empezaron a cantar y a dibujar en la tierra emblemas como la hoz y el martillo. Cuando los ronderos los escucharon,los padres fueron castigados y algunos niños retirados de la comunidad como supuestos "brujos" y entregados a instituciones benefactoras en calidad de huérfanos.

Los niños pasan por períodos de crisis con los padrastros o madrastras, y generalmente son el centro del conflicto porque son víctimas de agresiones y abandonos, entre otros. Hay casos de niños que son huérfanos totales y que fueron entregados a algunas familias, para su cuidado en general.

Algunos jóvenes fugaron voluntariamente y llegaron a los núcleos poblacionales más cercanos, siendo recibidos por sus familiares' (si los tenían)o acogidos por sus amistades o residentes. La siguiente canción nos relata el encuentro:

\section{Vamos a la guerra, \\ Vamos a luchar \\ $y$ volveremos triunfantes, \\ a nuestro pueblo.}

Los jóvenes que formaban parte del denominado "Ejército Guerrillero Popular" estaban retenidos en el "Frente Mayor", bajoestrictas medidas políticomilitares y sometidos a un permanente adoctrinamiento ideológico, lejos de sus hogares y familiares, mientras que sus padres sufrían y lloraban por la ausencia de sus hijos:

\section{Estoy Triste}

Hemos dejado a nuestra familia,

Tenemos pena,

Comenzamos a llorar de tristeza. 
Nosotros nos ponemos tristes,

Nunca veremos a nuestros hijos,

Padres, hermanos,

Qué vamos a ver ya.

Cómo estarán ellos allá,

ellos también estarán tristes,

Por nosotros y desesperados,

Pensarán ellos que nosotros,

Estamos muertos o que vivimos.

También ellos comenzarán

a cantar de tristeza,

¿dónde está?,mi padre,mi madre.

\section{Niranentaveta}

NONAMPIKI NARORI NOASHIRE TAKOTARO

NOSHINTO UPIAKA KATONKO

NARORI NOPUKAKE KIRINKA

\section{Estoy Llorando}

Estoy llorando por mis hijas

que he dejado en rio arriba

porque yo he venido a rio abajo.

Es la expresión de una madre desplazada que antes formó parte de la "masa" (7) en las filas de S.L. y que al huir hacia el Bajo Tambo llegó junto a su esposo e hijos menores, pero ella llora porque sus hijas jóvenes se quedaron detenidas en el "frente principal" en la zona del Alto Tambo, bajo control senderista.

Esta situación de guerra, ha conllevado a grandes pérdidas de vidas humanas, de ahí que muchas mujeres en ambos bandos han quedado viudas, niños huérfanos, también han muerto por enfermedades (TBC, cólera, desnutrición, EDA, IRA, etc). Hay casos en que sólo los varones han logrado fugar de las "bases de apoyo", dejando a sus esposas e hijos allí; cantan: 


\title{
YUVASHIRETANAKA NOTOMI NOJOKANAQUERI \\ APANIO MECA EIRO NIAJIROTSI IRINIRO IRIRI \\ IRITSIRO TICATSI MECA PAJEMPINE PIJARE \\ PISHONONKANE CUAJIKA ARIPIRANAJIA \\ PISHANINKA AVIRIRORI YOJOKANAQUEMPI
}

\author{
Estás triste, \\ porque tus familiares se mueren \\ y solo te quedas, \\ muy triste, \\ vas a llorar \\ quién te va a dar de comer \\ quién te va a dar ropa \\ vas a llorar.
}

Las preguntas se refieren a los roles sociales tradicionales divididos por género (varón / mujer); los varones y mujeres no pueden estar solos durante mucho tiempo, la organización social requiere de la familia como unidad principal: "En el grupo asháninka la unidad de producción en la cual se desarrollan las actividades productivas está constituida por la familia nuclear extendida, la que involucra a parientes por afinidad como el cuñado (ani), y el yerno (ñotsi)".(ROJAS Z.Enrique,1992:178/1994:88). De ahí que los varones y mujeres que enviudaron, rápidamente adquieren nuevos compromisos familiares.

Históricamente, los asháninka han visto amenazada su identidad cultural, agudizada ahora por el conflicto armado que protagoniza S.L., en el que algunos se sienten identificados y hacen suyas muchas canciones que las interpretan en voces muy bajas, veamos:

\section{"Adios pueblo de Ayacucho, perlaschallay \\ ya me voy, ya me estoy yendo perlaschallay \\ si en algún encuentro de esos, perlaschallay \\ me mataran, .... perlaschallay \\ moriré gritando,... perlaschallay"}

Expresiones del Yaraví, corregido y adaptado al estilo senderista, así mismo la canción "Flor de la retama" y "Hierba silvestre" entre otras , los asháninka las interpretan sentidamente, mencionan que "... tenían una responsable de canciones y que era Ayacuchana..." 


\section{PRESENCIA DE LA MUSICA ANDINA}

De otro lado, la vivencia cotidiana de las parejas y de aquellos jóvenes enamorados, interpretan diversas canciones del Folklore andino, que van desde los yaravíes ayacuchanos hasta los huaynos de la sierra de Lima que interpretan Flor Pileña, Alicia Delgado y Mina Gonzáles, situación a la que se suma las mulizas de la región Central de País, como las entonadas por Flor Pucarina, Picaflor de los Andes, Flor Sinqueña.

Estas canciones las interpretan generalmente las mujeres bilingües y muchas de ellas han salido a ciudades como Satipo, Mazamari o han trabajado en fundos agrícolas de colonos. Actualmente las sintonizan por emisoras radiales, tales como: Radio Quillabamba, Radio Huanta Dos Mil, Radio Altura de Cerro de Pasco y Radio Andina de Huancayo, entre otras.

Se caracterizan las composiciones por el sentido nostálgico, llenas de melancolías y sufrimiento tanto del varón y la mujer, así tenemos una letra al ritmo de Yaraví.

Negra del alma, negra de mi vida, cúrame la herida, que me has abierto dentro de mi pecho.

Cuando las uniones conyugales o los amoríos se ven resquebrajados por incomprensiones, alejamiento $\supset$ ausencia entonan:

Cuando me vaya,

lejos de este lugar

no llores más

por el amor que se va,

pero eso si

a nadie le contaré ese dolor

que llevo en mi corazón.

Esta situación, también se manifiesta cuando cantan y bailan los alumnos de los centros educativos bilingües en las diversas actuaciones, las danzas del Centro del Perú, como es el Santiago, el huaylash, los avelinos, la chonguinada, por medio de Cassettes y grabadoras o de las orquestas típicas como los Guapos 
del Centro, Sensación del Mantaro y los Super Mañaneros, entre otros y cuando las mujeres y varones bilingües interpretan las mulizas; veamos:

Cuando recuerdo tus caricias, Cuánto te extraño, amor mio.

Picaflor de los Andes

Los sentimientos emocionales a pesar de la violencia política, cantan al amor y a la desdicha; en el caso del varón:

Mírala cómo ha quedado,

la casita desolada

las flores que he cultivado

solitas se han marchitado...

Picaflor de los Andes

Cuando una pareja de desplazados, formó su compromiso familiar y ante la carestía de servicios y alimentos, sobrevenían las peleas y reconciliaciones y una mujer bilingüe muy nostálgica canturreaba:

En noche de Luna,

será cuando

retorne a tus brazos.....

Flor Pucarina

\section{INFLUENCIA DE LA CUMBIA FOLK TROPICAL ANDINA Y AMAZONICA}

Entre los jóvenes asháninka, hay una influencia muy fuerte de la "Chicha" llamada también cumbia Folk-tropical andina, de los conjuntos musicales denominados "Shapis", "Génesis". También la cumbia oriental de la amazonía Peruana, siendo "Sonido 2,000", "Fresa Ju venil", "Somos", "Caliz", "Juaneco y su combo", los grupos que suenan en las radio-grabadoras. La influencia cultural se remonta a varias décadas atrás, dada la presencia de colonos en la región y por las emisoras radiales "tropicales del recuerdo" como Radio Unión / Lima, Ondas del Huallaga, Radio Oriente de Yurimaguas y Radio Nuevo Mundo de Pucallpa, que son las más sintonizadas y llegan con nitidez. 
Inclusive, los músicos que interpretan los instrumentos musicales autóctonos como el tambor y la flauta, tienen una influencia de la cumbia oriental de estilo colombiano, también de la chicha y de los huaynos del centro y sur del país. Los bailan en reuniones familiares y en fiestas comunales.

\section{AÑORANZAS DEL PASADO}

Los asháninka desplazados, cantan también a la actividad cotidiana de antaño, como una añoranza a la libertad, para ir al monte a cazar y recolectar frutos, salir al río para pescar, ya que todavía, debido a la situación de violencia política, estas actividades son muy restringidas en la zona.

Los varones asháninkas, antes de internarse a los cerros (monte real) para proveerse de comida cantaban las canciones dirigidas a sus hijos y esposa, ejemplo:

\section{MECA NOJATE OTISHIQUIA}

TIQUEMISANTENA NOPANPUYÉ NIYOTERI

TAYKATSIRI OTISHIKI YAMAQUERO IBOSANUARE

IRIRAPISHITO YAVANINKAKA COMPERO ${ }^{(8)}$ PIÑABAJENA

NOPIAPIATAJE NOSHONKAJE NARORI NOQUEMETA

NOVESHIRIA NONAMPIQUI PAMENAJEYTAVAJENA ANTA OTSEMPEQUI APAROSATI PIQUEMAVAJENA NOVAN POYANE PAMAJERO.

\section{PARA IR AL CERRO}

Escúchame los gritos y mi canto

cuando voy al cerro,

vas a estar triste

con mis últimos cantos.

Van a recordar mi canto

cuando están tristes,

yo les mostraré mis canciones

lo que yo sé. 
Hay un pájaro, que trae su piri-piri

se pinta con lápiz la carita,

él me avisará todo.

Cuñada o suegra traeme masato

para tomar

mirenme todos,

cómo yo canto.

Esta canción también la cantaban al hijo que dejaban en el monte o le mandaban a cazar. Añaden, ellos también piensan y extrañan, lo mismo sucede a sus familiares.

Otras canciones expresan a la naturaleza, al mundo que les rodea, a los animales con sus encantos y bellezas.

\section{KATARI (9)}

KATARI YAMENATERI IJETARITE SHITIATARO TAMPONE

IPIPIATA KIRINKA ${ }^{(10)}$, KATONKO $^{(11)}$

NAMÉ, NAMÉ, NATIRI

YATARI NITORE TECATSI

INCANTIA KATARI VARI VARI.

\section{PAJARITO DEL AGUA}

Camina por las orillas del rio,

buscando peces,

regresa volando rio arriba y río abajo,

pero es bonito el pajarito,

sabe buscar su pescadito en el agua

yo le miro al pajarito,

bonito es viéndole de cerca.

Los desplazados asháninka, han sido obligados a permanecer en el núcleo poblacional por espacio de tres años por el comité de autodefensa, para probar si es verdad su arrepentimiento, además de una permanente observación y seguimiento. 
Parecería que los asháninka al interpretar las canciones dirigidas a las aves, quisieran olvidar su situación y ansiaran la libertad para volar libremente; su meta es salir de la zona a otra más tranquila, acogedora y dicen que ese lugar es su comunidad, que en algunos casos la idealizan en extremo -como que "ahí había todo,chacra,comida,casa, no nos faltaba,que los paisanos eran buenos,compartían,colaboraban...".

Desde antes de la violencia política, sus canciones se caracterizaban por ser tristes, porque sus esposos no llegaban del monte, no volvían del río, se angustiaban al no saber si estaban vivos o muertos, de ahí le cantaban a la soledad, al desamparo, entre otros temas.

\section{LA SITUACIÓN CULTURAL DE LOS ASHÁNINKA}

Al haber presentado la información testimonial de la población desplazada, consideramos que ésta se encuentra en un proceso intenso de aculturación aunque sus patrones culturales existentes se establecen en la cosmovisión e idiosincrasia étnica, ésta podría trastocarse agresivamente en las generaciones futuras.

Deotro lado, a pesar de que los asháninka en la actualidad cantan y bailan canciones andinas, tienen una actitud de rechazo total a los pobladores de la sierra, incluyendo a los profesores "choris", ${ }^{(12)}$ porque para ellos todos son potenciales representantes de SL, teniendo en cuenta que Sendero Luminoso es un movimiento político originado en la sierra einclusive sus altos mandos provienen de la misma región.

Los asháninka desplazados, expresan que "fueron engañados", porque les prometieron muchas cosas hasta que les convencieron, cuando se dieron cuenta descubrieron que habían sido utilizados en una "política sucia".

Los asháninka históricamente se han caracterizado por tener una comunicación oral, sus testimonios de vida quedan expresados en las canciones de acuerdo al momento coyuntural que atraviesan desde el nivel familiar al comunal. De ahí la importancia de recopilar cabalmente esta información, registrarla analíticamente para poder comprender su cosmovisión cultural.

Heise y Tubino (1994) señalan: "la memoria colectiva es importante en las sociedades de fuerte tradición oral, pero no ha de ser "santificada" con lo 
"propio" del grupo pues ésta es heterogénea con una diversidad de origenes. Coincidiendo con estos autores remarco mis discrepancias con aquellos investigadores y teóricos que bajo el argumento de "patrimonios culturales", "pueblos Indios" entre otros, pretenden concebir una sociedad antihistórica, momificada y cerrada a todos los otros grupos humanos (minorías nacionales), al puro estilo circense, y presentarlos como si fueran un museo para el deleite intelectual. Pues éstos ideólogos "conservacionistas", pretenden detener la rueda de la historia y empujarla para atrás, a costa de negarse a aceptar que toda cultura, en tanto realidad viviente, se encuentra en un constante proceso de transformación, cambio y apertura, negar estos hechos es faltarle el respeto a la libertad de su identidad cultural.

A través de las canciones apreciamos el proceso de integración y/o asimilación, según el caso, dentro del paradigma de la Interculturalidad, quese constituye en un desafío.

De un lado los asháninkas integran diversos géneros musicales, manteniendo su originalidad y adaptándolos a elementos nuevos según los modelos y valores étnicos, donde las diversas formas y concepciones vienen de dentro y fuera del grupo, aunque los aspectos más íntimos pueden tener diversos origenes, lo importante es que forman parte de la vida cotidiana de un pueblo sin disminuir su autoestima.

Finalmente, considero que no tenemos derecho de condenar a los asháninka ni a ningún grupo cul tural, encerrándolos en el bosque y obligándolos a vivir en el pasado, privándolos de elementos occidentales, por considerarlos nocivos y perniciosos. Ya que no todo lo que viene de fuera es malo, tampoco se trata de que lo acepten totalmente y se olviden de sus valores culturales y entendimiento. Además, toda esta problemática se enmarca en el modelo neoliberal, en donde las minorías nacionales tienden a sucumbir sino se alienan en función del mercado. La alternativa podría ser la integración de igual a igual, pero también siempre y cuando la cultura dominante sea positiva hacia la diversidad cultural y dependiendo también de las condiciones económicas, sociales, políticas y culturales y de otros factores que contribuyan a ese proceso. 


\section{CONCLUSIONES}

1. La situación de violencia política, generó el desplazamiento de comunidades enteras, unos se refugiaron en los núcleos poblacionales y otros cayeron bajo el control de S.L., estos últimos eran adoctrinados en las "escuelas populares", donde la población en general formaba parte de las "masas" y los jóvenes eran obligados a ser parte del "frente principal" como combatientes al servicio del "partido".

2. La férrea disciplina, las duras condiciones de vida y el riesgo de perder la vida en cualquier momento, al ver morir a muchos de ellos en las múltiples sanciones disciplinarias, asimismo en los ataques y emboscadas, propició que los asháninka fugaran de las huestes de S.L. Se presentaban en condición de arrepentidos en las guarniciones militares acantonadas en los núcleos poblacionales o los comités de autodefensa, donde eran interrogados y vigilados por los ronderos y la población, porque los consideraban infiltrados e informantes de Sendero.

3. En las postrimerías de 1991 se estimaba que unos 10,000 asháninka estaban prisioneros en los campamentos senderistas, luego de numerosos patrullajes de la autodefensa hacia las "zonas liberadas" y con el apoyo de las FF.AA., recuperaron a gran parte de la población en la actualidad se estima que quedan por liberar 4,000 asháninka.

4. Los arrepentidos y recuperados de las filas senderistas, dan testimonios de las condiciones de vida en las "Bases de Apoyo". Narran también las canciones de guerra que S.L. enseñaba a las mujeres, niños y niñas, como parte del adoctrinamiento ideológico-político y militar, tanto a jóvenes, niños y adultos. Actualmente, los asháninka en condición de refugiados, expresan a través de las canciones, sus sentimientos signados por el desarraigo familiar a causa de la pérdida de parejas, hijos, padres, etc.

5. La influencia cultural se remonta a varias décadas, que van desde las misiones religiosas, sectas de protestantes, madereros, colonizaciones dirigidas y no dirigidas, FF.AA., profesores colonos, comerciantes, medios de comunicación entre otros. Esto ha motivado que los asháninka hayan ingresado a un proceso de aculturación muy fuerte. Así se evidencia la música FolkTropical andina, más conocida como chicha, también los huaynos y danzas de la sierra centro y sur del país, inclusive los músicos autóctonos que interpretan la música en diversos géneros, como la cumbia, chicha, huayno, etc. 
6. La identidad Cultural del pueblo asháninka, pasa por un período de aculturación muy intenso a raíz de las múltiples influencias desde fuera, por lo que podrían sobrevenir cambios en las próximas generaciones trastocando en forma violenta los patrones culturales que escapan a la voluntad de las personas, siendo por lo tanto los asháninka los protagonistas de sus propios cambios culturales y por lo tanto creadores de su propio destino e historia.

\section{NOTAS}

(1) Selva Central.- Comprende a las provincias de Oxapampa (Dpto. de Pasco), Chanchamayo, Satipo en el Dpto. de Junín.

(2) Trocira.- Pequeño camino abierto en la espesura de la Selva.

(3) Nuicleo Poblacional - Conjunto de pobladores asháninka desplazados provenientes de diversas comunidades nativas.

(4) Preparación de la adolescente.- Ritual festivo preparado por los padres para la hija.

(5) Masato.- Bebida típica de la Selva, preparada por las mujeres en base a la yuca fermentada.

(6) Trampas Artesanales.- Tradicionalmente utilizadas por los asháninka para la caza, ahora utilizada como instrumento de guerra. Se trata de pozas donde se colocan estacas de chonta con la punta envenenada.

(7) Masa.-Término que emplea SL para los que forman parte de sus filas.

(8) Compero-- Pajarito de pecho y pico rojo con cabeza negra.

(9) Katari.-Pajaro acuático que se alimenta de pescado, zambulléndose en el agua por espacio de una hora.

(10) Kirinka.- Río arriba.

(11) Katonko.- Río abajo.

(12) Choris: Pobladores provenientes de la sierra,"cholos", término despectivo de los asháninkas

\section{BIBLIOGRAFIA}

ESPINOSA, OSCAR:

1994 A Los Asháninka: Guerreros en una historia de violencia. Inédito. Análisis de la Realidad, CAAAP, Lima-Perú.

1994 B Las rondas Asháninka y la violencia Política en la selva Central, Inédito. Análisis de la Realidad, CAAAP, Lima-Perú. 
FABIAN, BEATRIZ:

1994 "La Mujer Asháninka en un Contexto de Violencia Política", Amazonía Peruana No. 24, pp 289-316, CAAAP, Lima-Perú.

HEISE, MARIA / TUBINO, FIDEL / ARDITO, WILFREDO:

1994 Interculturalidad: Un desafío, $2^{\mathrm{a} E d i c}$. CAAAP, Lima-Perú.

LUNA, FABIOLA / VASQUEZ, NORMA / BEINGOLEA, MARTHA:

1992 Servidumbre o Conciencia: El dilema de la Formación, Ediciones CAAAP, Lima-Perú.

ROJAS ZOLEZZI, ENRIQUE:

1992 "Concepciones sobre las relaciones entre los géneros, mito, ritual y organización del trabajo en la unidad doméstica Campa-Asháninka". En: Amazonía Peruana No. 22, p 175-220, CAAAP. Lima-Perú

1994 Los Asháninka, un pueblo tras el bosque. Pontificia Univ. Católica del Perú, Fondo Editorial, Lima-Perú.

VARESE, ESTEFANO:

"La sal de los Cerros" (Una aproximación al mundo Campa). Ediciones Retablo de Papel, Lima-Perú.

\section{DIARIOS NACIONALES:}

1. El Peruano: Fechas 8 de Junio, 9, 11 y 27 de Julio, 1994, Lima-Perú.

2. La República: Junio / Julio 1994

\section{FUENTES ORALES:}

1. Entrevistas a Directivas de Clubes de Madres de los diversos sectores del río Tambo, 1993-1994

2. Conversaciones con mujeres asháninkas desplazadas, cuyas identidades guardamos en reserva.

3. Entrevistas a autoridades comunales, políticas y municipales. 